\title{
Электроосаждение металлов на $p$-Si из водных электролитов
}

\author{
(C) В.Н. Горяева, Р.А. Бисенгалиев
}

Калмыцкий государственный университет им. Б.Б. Городовикова, 358000 Элиста, Россия

E-mail: poltinnikd@mail.ru

Поступила в Редакцию 2 марта 2020 г.

В окончательной редакции 21 октября 2020 г.

Принята к публикации 9 ноября 2020 г.

Представлены особенности электрохимического осаждения металлических покрытий на $p$-Si и измерены свойства полученных металлических слоев. Исследована зависимость толщины обедненной области и внутреннего падения напряжения в ней от состава электролита и типа осаждаемого металла. Доказано влияние на свойства осадков, плотность тока и состав электролитов. Подбором предварительной обработки электролита и режима осаждения получены осадки металлов с приемлемой адгезией и малым продольным сопротивлением.

Ключевые слова: электрохимическое осаждение, $p$ - $\mathrm{Si}$, металлический слой, осаждение металлов.

DOI: 10.21883/FTP.2021.03.50611.9385

\section{1. Введение}

Металлические покрытия на полупроводниковых металлах широко используются в микроэлектронике. Электрохимический метод получения металлических слоев на полупроводниках является весьма простым, технологичным, легкоуправляемым, низкотемпературным и избирательным процессом, что делает его предпочтительным для ряда применений.

В данной работе представлены результаты исследования особенностей электрохимического осаждения [1] $\mathrm{Ag}, \mathrm{Co}, \mathrm{Cu}, \mathrm{Cr}, \mathrm{Zn}, \mathrm{Sn}, \mathrm{Ni}$ на $p$-Si и измерения свойств, получаемых металлических слоев.

\section{2. Методика эксперимента}

Использовались образцы площадью $0.5-1 \mathrm{~cm}^{2}$ из монокристаллического $p$-Si толщиной 0.3 мм ориентации (III) с удельным сопротивлением $\rho \sim$ $\sim 0.08-10$ Ом · см. Одна сторона образцов подверглась химико-механической полировке до получения оптически плоской поверхности. На другую (механически шлифованную) сторону для создания омического контакта напылялся и вплавлялся алюминий по обычной технологии. Перед осаждением металлов нерабочая сторона образцов покрывалась битумным или химически стойким лаком.

Осаждение металлов проводилось в открытой электрохимической ячейке на воздухе при комнатной температуре. Составы электролитов и токовые режимы осаждения представлены в табл. 1. Анодами служили пластины из того же металла, что и осаждаемый. Для улучшения качества осадка и прочности его сцепления с основой образцы кремния перед электроосаждением подвергались различным обработкам [2], указанным в табл. 2, и погружались в электролит под током. В некоторых случаях осаждение металлов стимулировалось освещением поверхности кремния светом лампы накаливания. После осаждения визуально и под микроскопом контролировался внешний вид осадков, измерялась их адгезионная прочность методом нормального отрыва и определялось их продольное электрическое сопротивление компенсационным четырехзондовым методом на постоянном токе при помощи моста Р307.

\section{3. Экспериментальные результаты}

В результате исследования найдено, что электрохимическое выделение металлов из водных растворов на $p$-Si часто требует значительных перенапряжений 1-30 В. Величина перенапряжения, необходимого для начала кристаллизации металлов, может быть снижена освещением поверхности кремния белым светом. Следовательно, на поверхности кремния в контакте с электролитом образуется обедненная область пространственного заряда и скорость осаждения металла ограничивается притоком неосновных носителей (электронов) и их генерацией вблизи поверхности, которая возрастает при освещении. Толщина обедненной области и внутреннее падение напряжения в ней зависят от состава электролита и типа осаждаемого металла.

Исследования показали, что подбором предварительной обработки электролита и режима осаждения можно получить хорошие, плотные, блестящие осадки всех указанных металлов (исключая хром) на $p$-Si c удовлетворительной адгезией. Предварительные обработки включали (см. табл. 2): обезжиривание (обработки А, В), освежение (C, C', G) и активизацию числа центров кристаллизации при электроосаждении, однако найдено, что адгезионная прочность осадков не увеличивается. Наиболее эффективной оказалась следующая последовательность обработок: В, C, D. Последняя обработка в растворе $\mathrm{D}$ хорошо очищает поверхность и дает улучшение адгезионных свойств осадков [3]. 
Таблица 1. Составы электролитов и режимы электрохимического осаждения металлов на кремний

\begin{tabular}{|c|c|c|c|c|c|}
\hline № состава & Металл & Составы электролита (г/л) & $\mathrm{ph}$ & Плотность тока $\left(\mathrm{A} / \mathrm{cm}^{2}\right)$ & Время (мин) \\
\hline 1 & $\mathrm{Ag}$ & $\mathrm{AgCl}-30, \mathrm{~K}_{4}\left[\mathrm{Fe}(\mathrm{CN})_{6}\right]-160, \mathrm{Na}_{2} \mathrm{CO}_{3}-20$ & 9.9 & $(1-4) \cdot 10^{-3}$ & $1-5$ \\
\hline 2 & $\mathrm{Ag}$ & $\mathrm{AgCl}-30, \mathrm{~K}_{4}\left[\mathrm{Fe}(\mathrm{CN})_{6}\right]-160, \mathrm{KCNS}-150$ & & $(1-4) \cdot 10^{-2}$ & 0.5 \\
\hline 3 & $\mathrm{Ag}$ & $\mathrm{AgCl}-60, \mathrm{KI}-450$ & & $(1-4) \cdot 10^{-2}$ & 0.5 \\
\hline 4 & $\mathrm{Cu}$ & $\mathrm{CuSO}_{4} \cdot 5 \mathrm{H}_{2} \mathrm{O}-8, \mathrm{H}_{2} \mathrm{SO}_{4}-4.9$ & & $(0.7-1) \cdot 10^{-2}$ & $30-60$ \\
\hline 5 & $\mathrm{Sn}$ & $\mathrm{SnCl}_{2} \cdot 2 \mathrm{H}_{2} \mathrm{O}-6.4, \mathrm{HCl}-13$ & & $1 \cdot 10^{-3}$ & 30 \\
\hline 6 & $\mathrm{Zn}$ & $\mathrm{Zn}_{2} \mathrm{P}_{2} \mathrm{O}_{7}-70, \mathrm{NaOH}-120$ & & $(1-3) \cdot 10^{-3}$ & 10 \\
\hline 7 & $\mathrm{Zn}$ & $\mathrm{ZnO}-120, \mathrm{NH}_{4} \mathrm{Cl}-350$ & & $(0.5-2) \cdot 10^{-2}$ & $10-40$ \\
\hline 8 & $\mathrm{Zn}$ & $\mathrm{ZnSO}_{4} \cdot 7 \mathrm{H}_{2} \mathrm{O}-50, \mathrm{HCl}-5, \mathrm{NaC}_{2} \mathrm{H}_{3} \mathrm{O}-5$ & & $(1-3) \cdot 10^{-3}$ & 10 \\
\hline 9 & $\mathrm{Ni}$ & $\mathrm{NiSO}_{4} \cdot 7 \mathrm{H}_{2} \mathrm{O}-250, \mathrm{NaCl}-10$ & 5.5 & $(1-2) \cdot 10^{-3}$ & 10 \\
\hline 10 & $\mathrm{Ni}$ & $\mathrm{NiSO}_{4} \cdot 7 \mathrm{H}_{2} \mathrm{O}-250, \mathrm{NaCl}-10, \mathrm{H}_{3} \mathrm{BO}_{3}-40, \mathrm{Na}_{2} \mathrm{SO}_{4}-100$ & 5.5 & $(1-4) \cdot 10^{-3}$ & 40 \\
\hline 11 & $\mathrm{Ni}$ & $\mathrm{Ni}\left(\mathrm{NH}_{2} \mathrm{SO}_{3}\right)_{2}-450, \mathrm{H}_{3} \mathrm{BO}_{3}-30$ & 5 & $(0.2-3) \cdot 10^{-2}$ & 20 \\
\hline 12 & $\mathrm{Ni}$ & $\mathrm{Ni}\left(\mathrm{BF}_{4}\right)_{2}-7, \mathrm{H}_{3} \mathrm{BF}_{4}-4$ & $2-3$ & $(0.4-1) \cdot 10^{-2}$ & 10 \\
\hline 13 & $\mathrm{Ni}$ & $\mathrm{H}_{3} \mathrm{BO}_{3}-30, \mathrm{NiSO}_{4} \cdot 7 \mathrm{H}_{2} \mathrm{O}-300, \mathrm{NaF}-6, \mathrm{NaCl}-15$ & 5.5 & $(0.4-1) \cdot 10^{-2}$ & 10 \\
\hline 14 & Co & $\mathrm{CoCl}_{2}-100, \mathrm{H}_{3} \mathrm{BO}_{3}-40$ & & $(1-3) \cdot 10^{-2}$ & 10 \\
\hline 15 & $\mathrm{Cr}$ & $\mathrm{CrO}_{3}-350, \mathrm{H}_{2} \mathrm{SO}_{4}-1.5, \mathrm{NaOH}-40$, caxap- 1 & & $(1-3) \cdot 10^{-2}$ & 10 \\
\hline 16 & $\mathrm{Cr}$ & $\mathrm{CrO}_{3}-16, \mathrm{~K}_{4} \mathrm{CrO}_{4}-0.24$ & & & \\
\hline 17 & $\mathrm{Cr}$ & $\mathrm{CrO}_{3}-16, \mathrm{~K}_{4} \mathrm{CrO}_{4}-0.24, \mathrm{HF}-20$ & & & \\
\hline
\end{tabular}

Таблица 2. Составы растворов, применяемые для обработки поверхности $p$-Si перед осаждением металлов

\begin{tabular}{|c|c|c|c|}
\hline Раствор & Состав раствора & Способ обработки & Время обработки (мин) \\
\hline A & Спирт этиловый & Промывка & $1-2$ \\
\hline B & Толуол & Промывка & $1-2$ \\
\hline $\mathrm{C}$ & $\mathrm{H}_{2} \mathrm{O}_{2}: \mathrm{NH}_{4} \mathrm{OH}: 4 \mathrm{H}_{2} \mathrm{O}$ (вода кипящая) & Выдержка в кипящем растворе & 5 \\
\hline$C^{\prime}$ & $\mathrm{H}_{2} \mathrm{O}_{2}: \mathrm{NH}_{4} \mathrm{OH}: 4 \mathrm{H}_{2} \mathrm{O}$ (вода холодная) & Выдержка в холодном растворе & 10 \\
\hline $\mathrm{D}$ & Насыщенный водный раствор $\mathrm{NH}_{4} \mathrm{~F}$ & Выдержка в растворе & \\
\hline $\mathrm{E}$ & $\mathrm{AgNO}_{3}-10$ г/л, $\mathrm{HF}(48 \%)-1$ г/л & Выдержка & $1-2 / 60$ \\
\hline $\mathrm{F}$ & Насыщенный раствор $\mathrm{K}_{2} \mathrm{Cr}_{2} \mathrm{O}_{7}$ в серной кислоте & Промывка & 0.5 \\
\hline G & $\mathrm{HNO}_{3}: \mathrm{HF}: \mathrm{H}_{2} \mathrm{O}$ & Выдержка & $1 / 6$ \\
\hline
\end{tabular}

Существенно влияют на свойства осадков плотность тока и состав электролита. При малых плотностях тока получаются тонкие, неровные, плохо сцепленные с основой осадки. При больших плотностях тока осадки становятся губчатыми, рыхлыми, с плохой адгезией. Составы электролитов варьировались при осаждении серебра, цинка, никеля. Наиболее эффективным оказались составы № 1 и 2 для серебра, № 6 для цинка и № 13 для никеля (см. табл. 1).

\section{4. Обсуждение результатов}

Результаты экспериментального определения адгезионной прочности $A_{e}$ электрохимических осадков металлов на кремний и их продольного электрического сопротивления $R_{e}$ вместе с теоретически рассчитанными значениями $A_{t r}$ и $R_{t r}$ приведены в табл. 3. Видно, что экспериментальные величины продольного сопротивления удовлетворительно совпадают с теоретическими, если полагать 100-процентный выход по току. Экспериментальные значения адгезионной прочности также близки к теоретическим, рассчитанным по формуле (1):

$$
A_{t r}=0.9 \cdot 10^{-14} \varepsilon \cdot E^{2}
$$

где $E=L \delta$ - напряженность электрического поля на границе металл-полупроводник, $U_{c}$ - контактная разность потенциалов, $\varepsilon, \delta$ - диэлектрическая проницаемость зазора и его толщина. Предполагалось $\varepsilon=10$, $\delta=10 \AA ̊$. Величины $U_{c}$ для расчетов определялись экспериментально. Небольшие значения адгезионной прочно-

Таблица 3. Параметры электрохимических осадков металлов на $p$-Si

\begin{tabular}{c|c|c|c|c|c|c}
\hline Металл & $\begin{array}{c}d, \\
10^{-4} \mathrm{~cm}\end{array}$ & $\begin{array}{c}R_{e}, \\
10^{-2} \text { Ом/M }\end{array}$ & $\begin{array}{c}R_{t r}, \\
10^{-2} \text { Ом/M }\end{array}$ & $\begin{array}{c}U_{c}, \\
\mathrm{~B}\end{array}$ & $\begin{array}{c}A_{e}, \\
10^{4} \Pi \mathrm{a}\end{array}$ & $\begin{array}{c}A_{t r}, \\
10^{4} \text { Па }\end{array}$ \\
\hline $\mathrm{Ag}$ & 0.4 & 5 & 4 & 0.2 & 7.8 & 1.2 \\
$\mathrm{Cu}$ & 0.16 & 2 & 1 & 0.5 & 3 & 9 \\
$\mathrm{Ni}$ & 0.4 & 1.7 & 1.2 & - & 1 & 6 \\
$\mathrm{Zn}$ & 0.85 & 6.7 & 6.9 & 0.9 & 100 & 30 \\
$\mathrm{Sn}$ & 0.2 & 74 & 60 & 0.6 & 51 & 21 \\
$\mathrm{Co}$ & 0.01 & - & - & 0.7 & 19 & 24
\end{tabular}


сти, наблюдаемые для $\mathrm{Ag}, \mathrm{Cu}, \mathrm{Ni}$, объясняются небольшой величиной $U_{c}$. Наибольшая величина $A_{e}$ наблюдается для $\mathrm{Zn}$ и $\mathrm{Sn}$. Адгезионную прочность можно увеличить путем отжига контактов в вакууме при температуре $400-500^{\circ} \mathrm{C}$ в течение 5-10 мин. Измерения электрических характеристик структур показали, что образуются выпрямляющие контакты с промежуточным слоем толщиной $\delta=10 \AA$.

\section{5. Заключение}

Таким образом, в работе было испытано 17 составов электролитов и 9 различных обработок для электрохимического осаждения $\mathrm{Ag}, \mathrm{Co}, \mathrm{Cu}, \mathrm{Zn}, \mathrm{Sn}$ и $\mathrm{Ni}$ на $p$-Si из водных растворов. Показано, что подбором предварительной обработки поверхности и режима осаждения можно получить осадки металлов с удовлетворительной адгезией (до $\sim 10^{6}$ Па) и малым продольным сопротивлением $\left(<10^{-1} \mathrm{OM} / \mathrm{M}\right)$. При электроосаждении исследованных металлов на $p$-Si $(\rho=1$ Ом · см) получаются выпрямляющие контакты с высотой барьера $U_{c}=(0.07-0.9)$ эВ, причем $U_{c}$ возрастает в ряду $\mathrm{Ag}$, $\mathrm{Ni}, \mathrm{Cu}, \mathrm{Sn}, \mathrm{Co}, \mathrm{Zn}$. Зазор между металлом и полупроводником оценочно составляет $10 \AA$.

\section{Конфликт интересов}

Автор заявляет, что у него нет конфликта интересов.

\section{Список литературы}

[1] Р.М. Вишомирскис. Кинетика электроосаждения металлов из комплексных электролитов (М., Наука, 1969).

[2] В.М. Замурников, Н.А. Костин. Гальванотехника и обработка поверхности, 3, 34 (1994).

[3] А.Д. Зимон. Адгезия пленок и покрытий (М., Химия, 1977).

Редактор А.Н. Смирнов

\section{Electrodeposition of metals on $p$-Si from aqueous electrolytes}

\section{V.N. Goriaeva, R.A. Bisengaliev}

Kalmyk State University named after B.B. Gorodovikov, 358000 Elista, Russia

Abstract The features of electrochemical deposition of metal coatings on $p$-Si are presented, and the properties of the obtained metal layers are measured. The dependence of the thickness of the depleted region and the internal voltage drop in it on the composition of the electrolyte and the type of precipitated metal was investigated. The effect of current density and electrolyte composition on the properties of precipitation is proved. By selection of the electrolyte pretreatment and the deposition mode, metal precipitates with acceptable adhesion and low longitudinal resistance were obtained. 